\title{
GC-MS Analysis of Bioactive Compound in Ethanolic Extract of Pithecellobium dulce Leaves
}

\author{
Anil F Bobade* \\ Department of Industrial Chemistry, Arts, Science and Commerce College, Chikhaldara, Maharashtra, India \\ *Corresponding Author: Anil F Bobade, Department of Industrial Chemistry, Arts, Science and Commerce College, Chikhaldara, \\ Maharashtra, India.
}

Received: September 17, 2019; Published: October 04, 2019

DOI: $10.31080 /$ ASPS.2019.03.0412

\begin{abstract}
Pithecellobium dulce has been utilized by antiquated individuals in treating various sorts of ailments due to its restorative properties. Extract of leaves is employed as a remedy for indigestion and to prevent spontaneous abortion and for gall bladder ailments and to treat both open and closed wounds. Soxhlet-extraction with ethanol and the extract analysed using a GC-MS followed by concentration in rotary evaporator. The GCMS analyse major phytochemical compounds in Pithecellobium dulce leaves extract. The phytoconstituents were13Docosenamide, (Z); Cyclohexasiloxane, dodecamethyl, Cyclodecasiloxane, eicosamethyl;methyl ester exadecanoic acid, Cyclodecasiloxane, eicosamethyl, Hexadecanoic acid. L- Lysine, 1Monolinoleoylglycerol trimethylsilyl ether, Rhodopin.
\end{abstract}

Keywords: GC-MS; Soxhlet; Rotary Evaporator; Chemical Composition

\section{Introduction}

Pithecellobium dulce is used as medicinal plant. An extract of the leaves is used for gall ailments and to prevent miscarriage. Pithecellobium dulce is a species of flowering as well as fruit bearing plant has family fabaceae [1]. Often planted for living fence or thorny hedge, eventually nearly impenetrable, guamachil furnishes food, forage, and firewood, while fixing a little nitrogen. The pods, harvested in Mexico, Cuba, and Thailand, and customarily sold on roadside stands, contain a thick sweetish, but also acidic pulp, eaten raw or made into a drink similar to lemonade. Pods are devoured by livestock of all kinds; the leaves are browsed by horses, cattle, goats, and sheep; and hedge clippings are often gathered for animal feed. Reported to be abortifacient, anodyne, astringent, larvicidal, guamachil is a folk remedy for convulsions, dysentery, dyspepsia, earache, leprosy, peptic ulcers, sores, toothache, and venereal disease [2]. The bark of $P$. avaremotem, the "avaremo-temo" from Brazil, is a folk cancer elixir [3]. Pods contain a pulp that is variously sweet and acid, commonly white but also red. The seed and pulp are made into a sweet drink similar to lemonade and also eaten roasted or fresh. The seeds are used fresh in curries in India. The leaves can be applied as plasters for pain and veneral sores. The plant is used for hundreds of years in Ayurvedic medicine with no reported toxicity [4].

\section{Material and Method \\ Collection of plant material}

The fresh leaves of Pithecellobium dulce plant were collected from Melghat region Dist-Amravati (Maharashtra) The experimental site is located between coordinates $20.91^{\circ} \mathrm{N}, 77.75^{\circ} \mathrm{E}$ and an altitude of $312 \mathrm{~m}$ in foothills of Central India experiencing the subtropical climate during winter season in the month December 2014 and the Authentication of plant was confirmed by botanist (Prof. S.R. Kadu, Department of Botany, Art, Commerce and Science College Chikhaldara).

\section{Preparation of plant extract}

The plant were dried over ambient temperature and the dried sample were grind properly and dried powder sample was extracted in Methanol at $65^{\circ} \mathrm{C}$, by using soxhlet apparatus [5] and extracts were concentrated by gradually evaporating the respective solvent on rotary evaporator. The concentrated extract was collected in sterile bottles and kept in a cool and dark place prior to analysis.

\section{GC-MS Analysis of Pithecellobium dulce}

Gas Chromatography and Mass Spectroscopy

A JEOL GCmate II benchtop double-focusing magnetic sector mass spectrometer operating in electron ionization (EI) mode with 
TSS-2000 [1] software was used for all analyses. Low-resolution mass spectra were acquired at a resolving power of $1000(20 \%$ height definition) and scanning from $\mathrm{m} / \mathrm{z} 25$ to $\mathrm{m} / \mathrm{z} 700$ at $0.3 \mathrm{sec}$ onds per scan with a 0.2 second inter-scan delay. High resolution mass spectra were acquired at a resolving power of $5000(20 \%$ height definition) and scanning the magnet from $\mathrm{m} / \mathrm{z} 65$ to $\mathrm{m} / \mathrm{z}$ 750 at 1 second per scan.
Identification of chemical constituents

Identification of the chemical constituents was done on the basis of retention index (RI) using a mass spectra library search NIST and by com-paring the mass spectral and retention data with literature. The relative amounts of individual components were calculated based on the GC peak area (FID response) without using a correction factor.

\begin{tabular}{|l|c|c|c|c|}
\hline Sr. No & Rention Time & Name of chemical constituent & Molecular Formula & Peak Area \% \\
\hline 1 & 10.75 & $\begin{array}{c}\text { Cyclohexasiloxane, } \\
\text { dodecamethyl }\end{array}$ & C12H3606Si6 & 2.52 \\
\hline 2 & 18.25 & Cyclodecasiloxane, eicosamethyl & C20H60010Si10 & 2.62 \\
\hline 4 & 25.15 & 13Docosenamide, $(Z)$ & C22H43NO & 37.69 \\
\hline 6 & 29.15 & Hexadecanoic acid & C36H5806 & 2.79 \\
\hline 7 & 31.06 & L-Lysine & C53H72N809 & 2.62 \\
\hline 8 & 31.62 & Rhodopin & C40H580 & 1.48 \\
\hline 8 & 32.62 & Milbemycin b & C27H5404Si2 & 2.13 \\
\hline 9 & 33.16 & $\begin{array}{c}\text { 1Monolinoleoylglycerol } \\
\text { trimethylsilyl ether }\end{array}$ & \\
\hline
\end{tabular}

Table 1: Chemical Composition of Pithecellobium dulce leaves.

CIL/ SAIF Panjab University Chandigarh

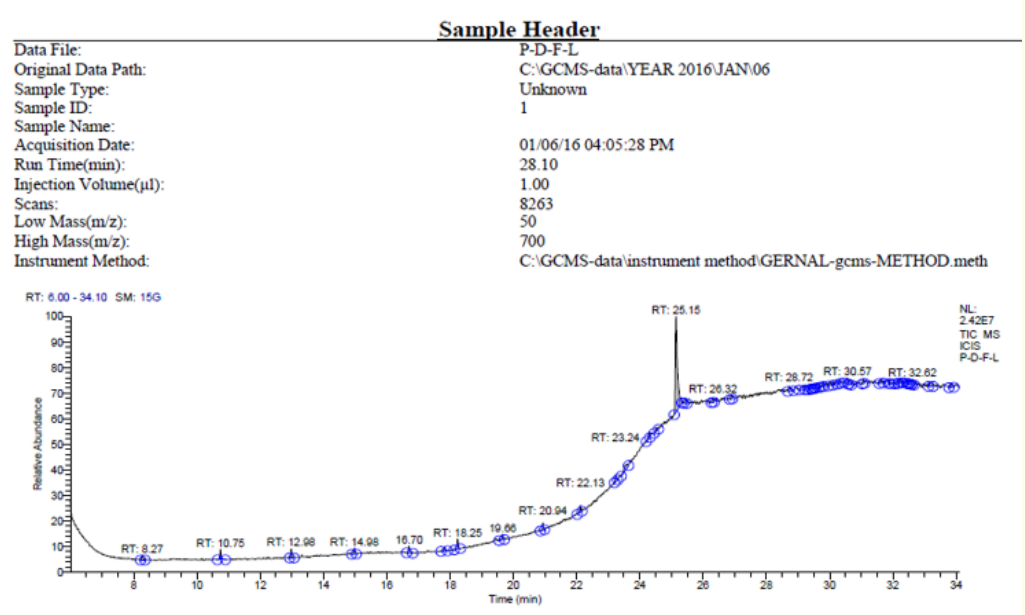

\section{CIL/ SAIF Panjab University Chandigarh}

Library Search Results Table

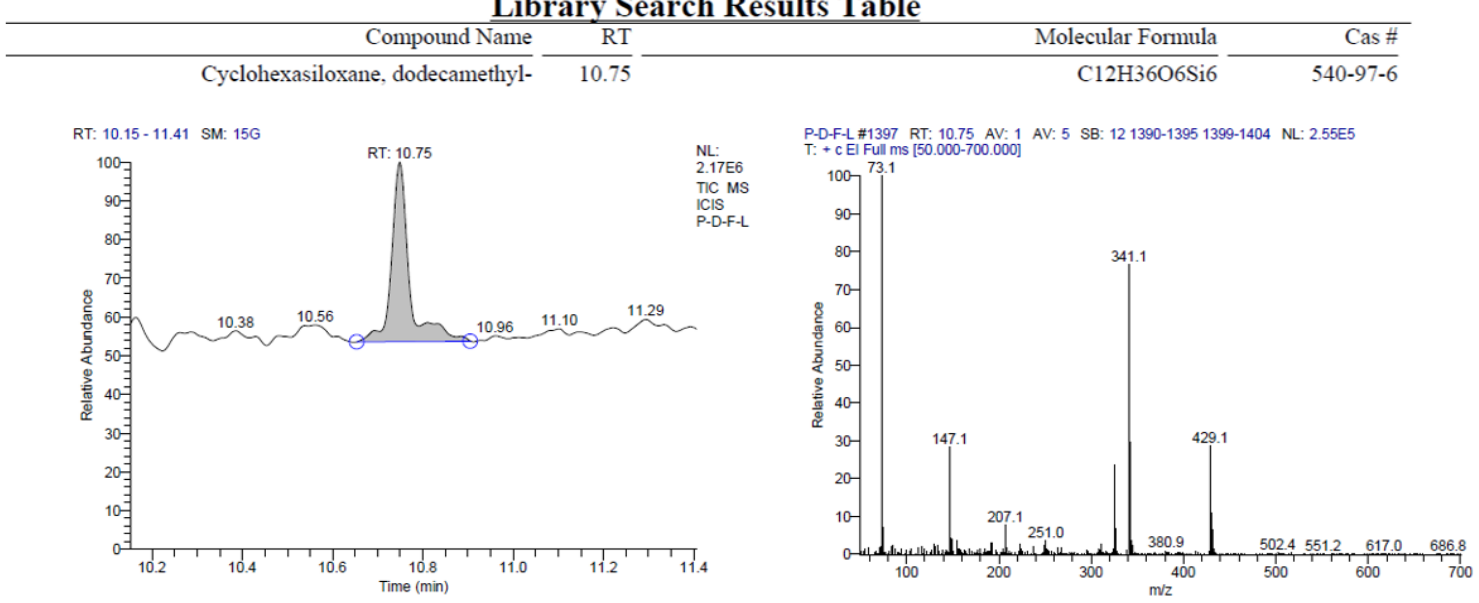


CIL/ SAIF Panjab University Chandigarh
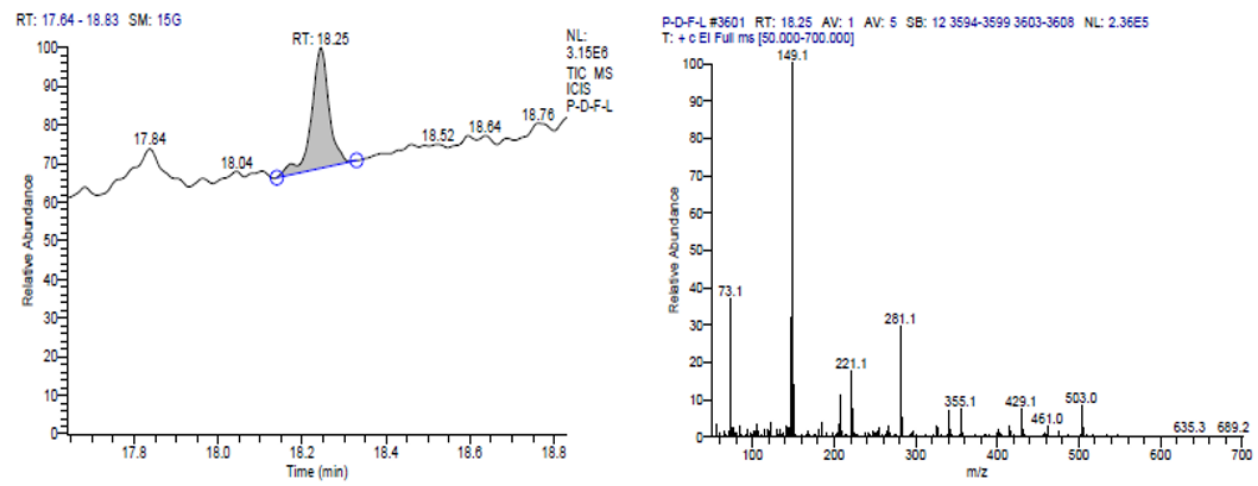

Library Search Results Table

\begin{tabular}{rrrr}
\hline Compound Name & RT & Molecular Formula & Cas \# \\
Cyclodecasiloxane, eicosamethyl- & 18.25 & C20H60010Si10 & $18772-36-6$
\end{tabular}

\section{CIL/ SAIF Panjab University Chandigarh}
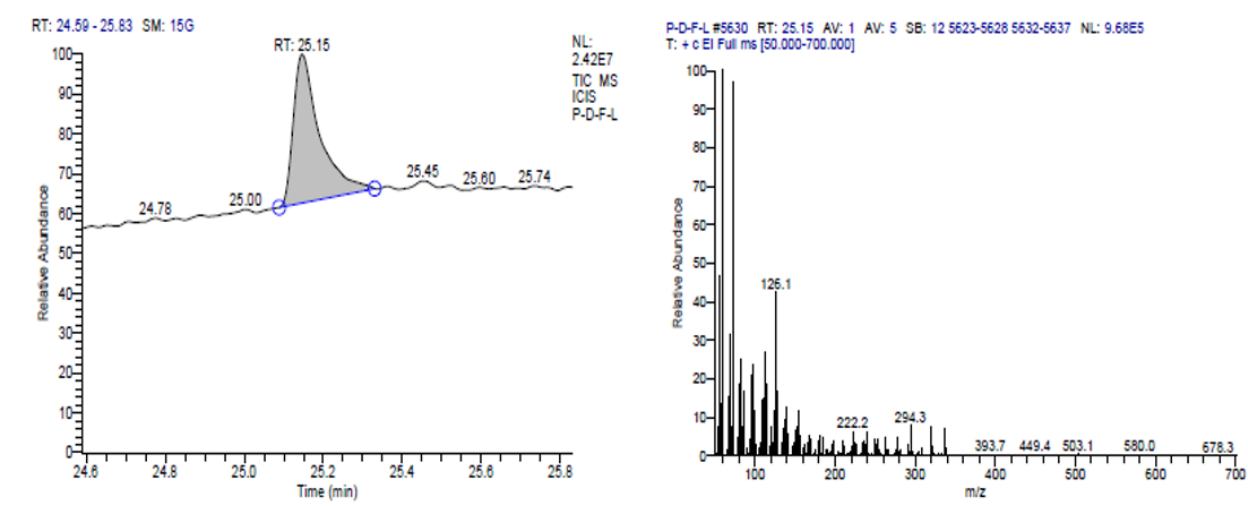

Library Search Results Table

\begin{tabular}{|c|c|c|c|}
\hline Compound Name & $\frac{R}{R T}$ & Molecular Formula & $C_{3 \mathrm{~S}} \#$ \\
\hline 13-Docosenamide, (Z)- & 25.15 & $\mathrm{C} 22 \mathrm{H} 43 \mathrm{NO}$ & $112-84-5$ \\
\hline
\end{tabular}
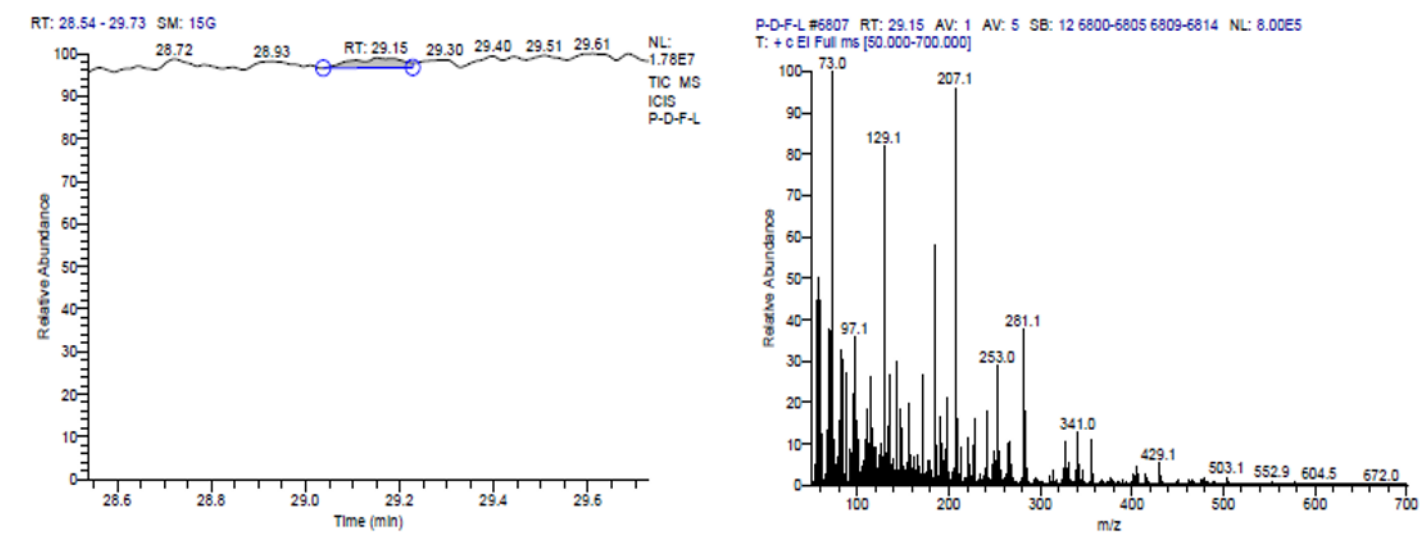

Library Search Results Table

\begin{tabular}{|c|c|c|}
\hline Compound Name & Molecular Formula & Cas \# \\
\hline Hexadecanoic acid. & $\mathrm{C} 36 \mathrm{H} 58 \mathrm{O} 6$ & $557-26-3$ \\
\hline
\end{tabular}



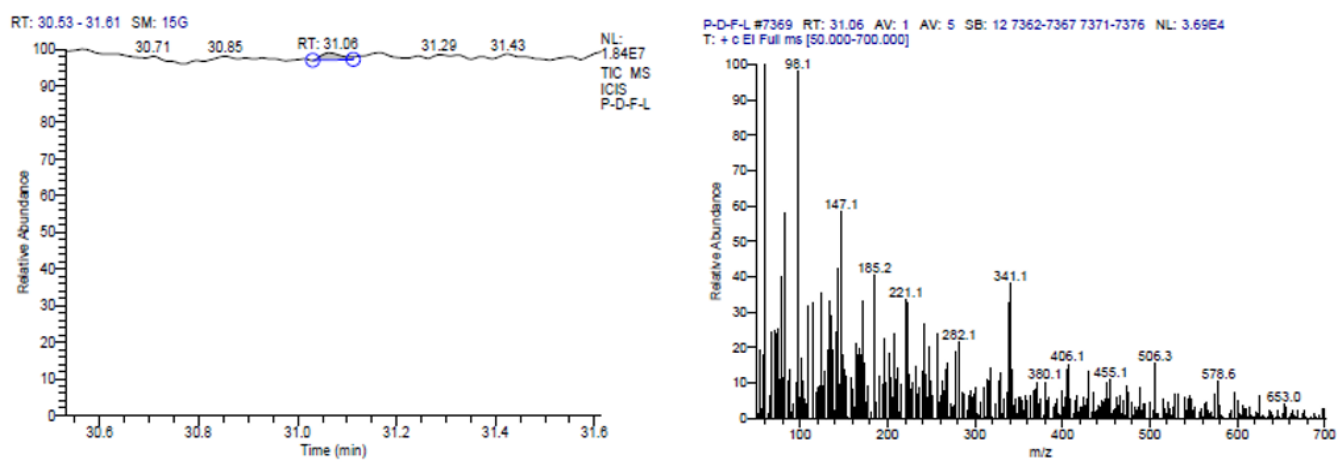

CIL/ SAIF Panjab University Chandigarh

Library Search Results Table

\begin{tabular}{rrrr}
\multicolumn{2}{c}{ Library Search Results Table } & Molecular Formula & Cas \# \\
\hline Compound Name & RT & C53H72N809 & $56818-04-3$
\end{tabular}
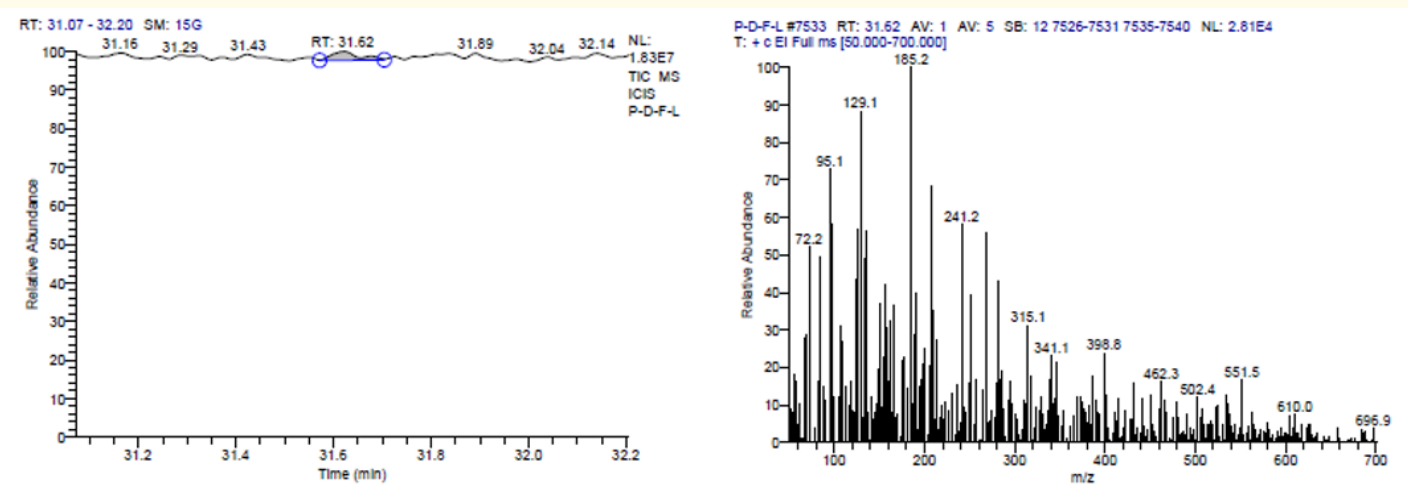

Library Search Results Table

\begin{tabular}{rrrrr}
\hline Compound Name & RT & Molecular Formula & Cas \# \\
Rhodopin & 31.62 & C40H58O & $105-92-0$
\end{tabular}
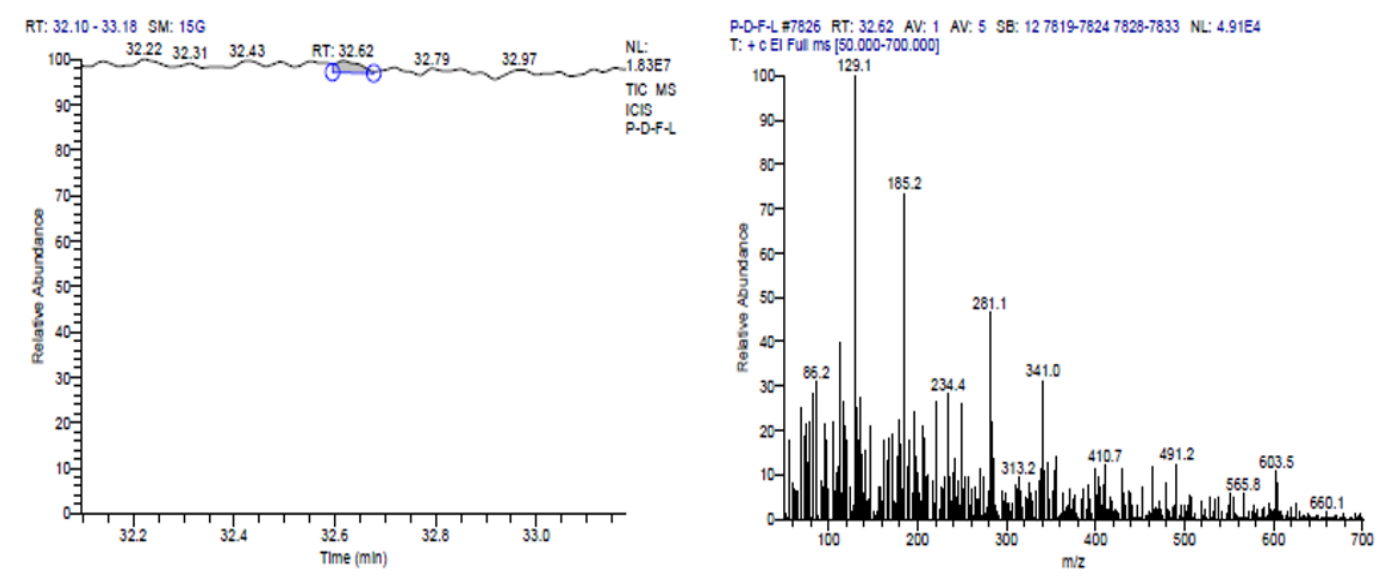

Library Search Results Table

\begin{tabular}{rrrr}
\hline Compound Name & RT & Molecular Formula & Cas \# \\
\hline Milbemycin b, & 32.62 & C33H46CINO7 & $107024-98-6$
\end{tabular}



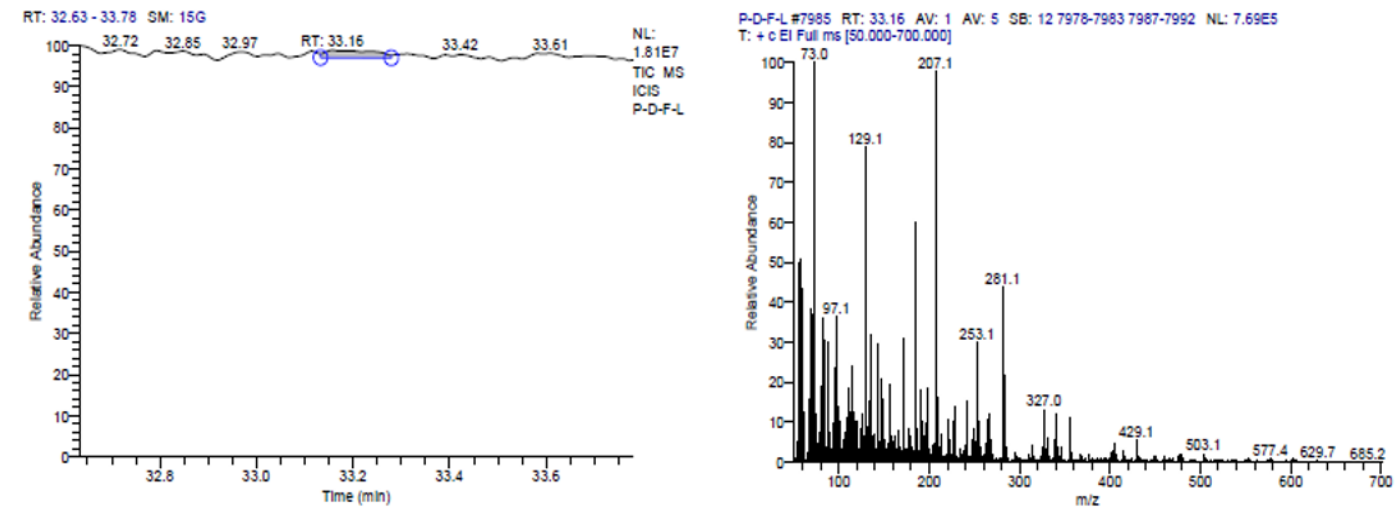

\section{CIL/ SAIF Panjab University Chandigarh}

\section{Library Search Results Table}

\begin{tabular}{rrrr}
\hline Compound Name & RT & Molecular Formula & Cas \# \\
\hline 1-Monolinoleoylglycerol trimethylsilyl ether & 33.16 & C27H5404Si2 & $54284-45-6$ \\
\hline
\end{tabular}

\section{Result and Discussion}

GC-MS chromatogram analysis of the Methanolic extract of Pithecellobium dulce Figure 1 showed major nine peaks which indicating the presence of verious phytochemical constituents. On comparison of the mass spectra of the constituents with the NIST library. The various phytochemicals which contribute to the medicinal activities like Hepato protective activity, antimicrobial, antifungal, antiviral and antioxidents. The mass spectra of all the phytochemicals identified in the whole plant the most prevailing compounds were Cyclohexasiloxane, dodecamethyl [6] (2.52\%); Cyclodecasiloxane, eicosamethyl (2.62\%) Tetracosamethyl-cyclododecasiloxane is one of the biologically active compound possessed hepato protective activity [7] and antispasmodic, antirheumatic, anti-soporific baths, insecticides for mosquito control, appetizing agent, to combat indigestion, stomach pain, nausea and infection of the gall bladder [8]. Mosquito repellent compounds [9]; 13Docosenamide, (Z)- (37.69\%) which shows antimicrobial activity [10]; Hexadecanoic acid (2.79\%) Antibacterial and antifungal, antioxidant hypo-cholesterolemic, nematicide, insecticide lubricant, anti-androgenic flavor, hemolytic [11]; L-Lysine (2.62\%) Studies show that Lysine helps build collagen in the skin. Collagen is the structure responsible for your skin's elasticity and firmness [12]; Rhodopin(1.48\%) major compouds in phototrophic bacteria [13]; Milbemycin b (1.46\%) is a group of macrolides chemically related to the avermectins. They are used in veterinary medicine as antiparacitic agents against worms, ticks and fleas [12]. 1Monolinoleoylglycerol trimethylsilyl ether (2.13\%) also shows Antimicrobial Antioxidant Antiinflammatory Antiarthritic Antiasthma, Diuretic [14].

\section{Conclusion}

The phytochemical analysis of the crude extracts presence of various bioactive compounds in the Pithecellobium dulce justifies the use of whole plant for various ailments by traditional practitioners. However, isolation of individual phytochemical constituents will definitely give fruitful results. From the results, it could be concluded that Pithecellobium dulce contains various bioactive compounds. Therefore, Pithecellobium dulce exhibit significant support folkloric use of this plant leaves; corroborating the importance of ethno pharmacological selection of plants.

\section{Bibliography}

1. Felker P. "Uses of tree legumes in semiarid regions". Economic Botany 35 (1981): 174-186.

2. Duke JA. "Ecosystematic data on economic plants". Quarterly Journal of Crude Drug Research 17 (1979): 91-110.

3. Hartwell JL. "Plants used against cancer. A survey". Lloydia (1971): 30-34.

4. Sugumaran M., et al. "Free Radical Scavenging Activity of Folklore: Pithecellobium dulce Benth. Leaves". Ethnobotanic Leaflet 12 (2008): 446-451.

5. Umesh Khandekar., et al. "Screening on antioxidant activity, antimicrobial activity and phytoconstituents of Cyathocline lyrata leaf". International Journal of chemical and pharmaceutical sciences 4 (2013): 64-68. 
6. Screening Assessment for the Challenge Dodecamethylcyclohexasiloxane (D6) Chemical Abstracts Service Registry Number 540-97-6Environment Canada Health Canada (2008).

7. Babalola 00., et al. "Hepato protective activity of aqueous extract of the leaves of Hyptis suaveolens (l.) Poit on acetaminophen induced hepato toxicity in rabbits". Research Journal of Chemical Sciences 1 (2011): 85-88.

8. Singh HB and Handique AK. "Antifungal activity of the essential oil of Hyptis suaveolens and its efficacy in bio control measures in combination with Trichoderma harzianum". 9 (2007): 683-87.

9. Venugopal G., et al. "GC-MS analysis and in silico molecular docking studies of mosquito repellent compounds from Hyptis suaveolens L". International Journal of Bioassays 1 (2012): $36-41$

10. Norliana Ghajali., et al. "Gc-ms analysis of some bioactive components In the root extract of ixora coccinea linn". International Journal of Pharma and Bio Sciences 5 (2014): 197-203.

11. Arora Sunita., et al. "Gas Chromatography-Mass Spectrometry Analysis of an Endangered Medicinal plant, Sarcostemma Viminal (L)R.BR. From Thar Desert, Rajasthan (India)". Asian Journal of Pharmaceutical and Clinical Research 10 (2017): 210-213.

12. P Yamuna., et al. "GC-MS analysis of bioactive compounds in the entire plant parts of ethanolic extract of Gomphrena decumbens Jacq". Journal of Medicinal Plants Studies 5 (2017): 31-37.

13. The 2nd International Electronic Conference on Synthetic Organic Chemistry: Insecticides Archived (2008).

14. Parthipan B., et al. "GC-MS Analysis of Phytocomponents in Pleiospermiumalatum (Wall. ex Wight and Arn.) Swingle, (Rutaceae)". Journal of Pharmacognosy and Phytochemistry 4 (2015): 216-222.

Volume 3 Issue 11 November 2019

(C) All rights are reserved by Anil F Bobade. 